\title{
Pulmonary langerhans cell histiocytosis: Two cases with varied radiologic findings
}

\author{
Hulya Gunbatar ${ }^{1, *},{\text { Alpaslan } \text { Yavuz }^{2} \text {, Bunyamin Sertogullarindan }}^{1}$, Selami Ekin ${ }^{1}$, Selvi Asker $^{1}$, \\ Fuat Sayır ${ }^{3}$, Irfan Bayram ${ }^{4}$
}

\author{
${ }^{1}$ Department of Pulmonary and Critical Care, Yuzuncu Yil University Medical Faculty, Van, Turkey \\ ${ }^{2}$ Department of Radiology, Yuzuncu Yil University, Medical Faculty, V an Turkey \\ ${ }^{3}$ Department of Pulmonary Surgery, Y uzuncu Yil University Medical Faculty, Van Turkey \\ ${ }^{4}$ Department of Pathology, Yuæuncu Yil University Medical Faculty, Van Turkey
}

\begin{abstract}
Pulmonary Langerhans Cell Histiocytosis (PLCH) is an idiopathic interstitial lung disease with Langerhans cell infiltration in the lung. PLCH X has non-spesific symptoms, and most patients have smoking history. A combination of stellate nodules, reticular and nodular opacities, upper zone cysts or honeycombing, preservation of lung volume and costophrenic angle sparing are highly specific for PLCH. To contribute to the literature, two cases are presented. First case is 30 years old man with 10 pack/years smoking history was admitted with cough and persevering interstitial opacities. Second case is 34 years old man with 15 pack/years smoking history was admitted with persistant cough. On thorax CT the first case had reticulonodular opacities at the perifery of the upper and middle zones, second case had multiple parenchymal cystic nodular lesions. Open lung biopsy performed, immunohistochemical examination CD1a, CD68, S100 detecting antigenpositive and histologically and radiologically confirmed diagnosed of PLCH.
\end{abstract}

Key Words: Pulmonary Langerhans cell histiocytosis, radiology, histology

\section{Introduction}

Pulmonary Langerhans Cell Histiocytosis (PLCH) is a rare form of interstitial lung diseases that primarily affects young adults (1-5). The certain incidence and prevalence are unknown. No occupational or geographic predisposition has been reported, but majority of the affected population have a history of ongoing or past smoking. The Langerhans cell is the pathologic cell type of PLCH. Langerhans cells also demonstrate positive immunohistochemical staining for S100 protein and have strong presence of CD1 antigen (CD1a) on the cell surface. Patients with PLCH are mostly determined by sole or combination of several altered presentations such as; incidentally detected findings on chest radiographs including a spontaneous pneumothorax and/or with respiratory or constitutional symptoms (6,7). High resolution computed tomography (HRCT) of the chest can provide significant data to lead the diagnosis. A combination of the features such as stellate nodules lung volume and costophrenic angle sparing are highly specific for PLCH $(8,9)$. Because of the rarity; we reported the varied radiological features of two cases with a histologically and radiologically confirmed diagnosed of PLCH.

\section{Case report}

Case 1: A 30 years old man referred with a two month history of dyspnea, cough, sputum and night sweats. Before his admission, he had an antibiotherapy in another epicenter, his complaints have regressed. He was referred to our hospital because of the persevering abnormalities detected on chest radiographs. On his initial admission; physical examination and routine hematology parameters including ESR were within normal ranges (ESR was 7 $\mathrm{mm}$ at the end of first hour). Sputum cultures including for tuberculosis were negative. Blood gases and pulmonary function tests were normal. In anamnesis, he had a 10 pack/year smoking history. The chest X-ray revealed reticulonodular opacities at the perifery of the upper and middle zones. In thorax computed tomography (CT) examination; pulmonary parenchymal nodules with a range of $1-5 \mathrm{~mm}$ in diameter were detected, lesions were mostly with centrilobular distribution (arrows), but a few were located at subpleural region (arrow head). Magnified investigation of the pulmonary parenchyma on chest CT revealed central hypo-dense components leading cavitation (Image 1a,b). Open lung biopsy performed to the patient, immunohistochemical examination 
CD1a, CD68, S100 detecting antigen-positive and langerhans cell histiocytosis diagnosed (Figure 1 a,b,c). Fluorodeoxyglucose-PET (FDG-PET) was performed the patient for determining the systemic involvement, FDG PET imaging was negative. Smoking cessation was recommended, he stopped smoking and still in follow up.
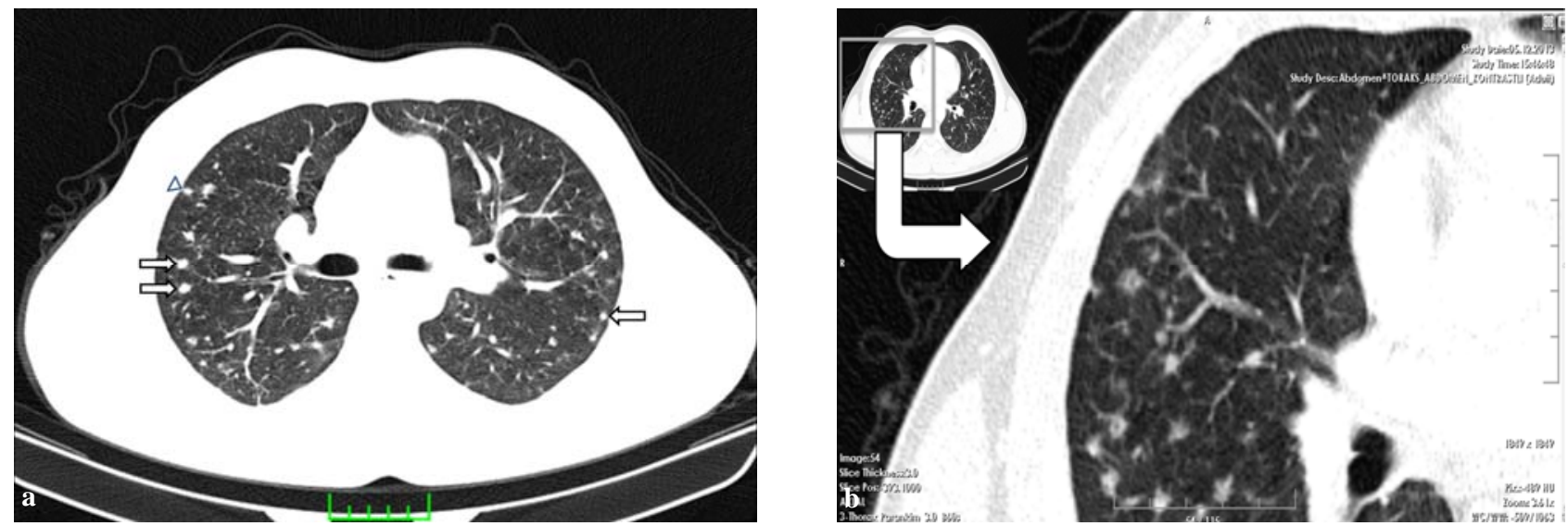

Image 1. Chest CT image from a 27-year-old smoker male with biopsy-proven Pulmonary Langerhans cell histiocytosis demonstrating multiple pulmonary nodules which mostly pronounced early in the disease. a) Nodules were 1-5 $\mathrm{mm}$ in diameter, mostly with centrilobular distribution (arrows), but a few were located at subpleural region (arrow head). b) Magnified examination on chest CT revealed central hypo-dense components leading cavitation.
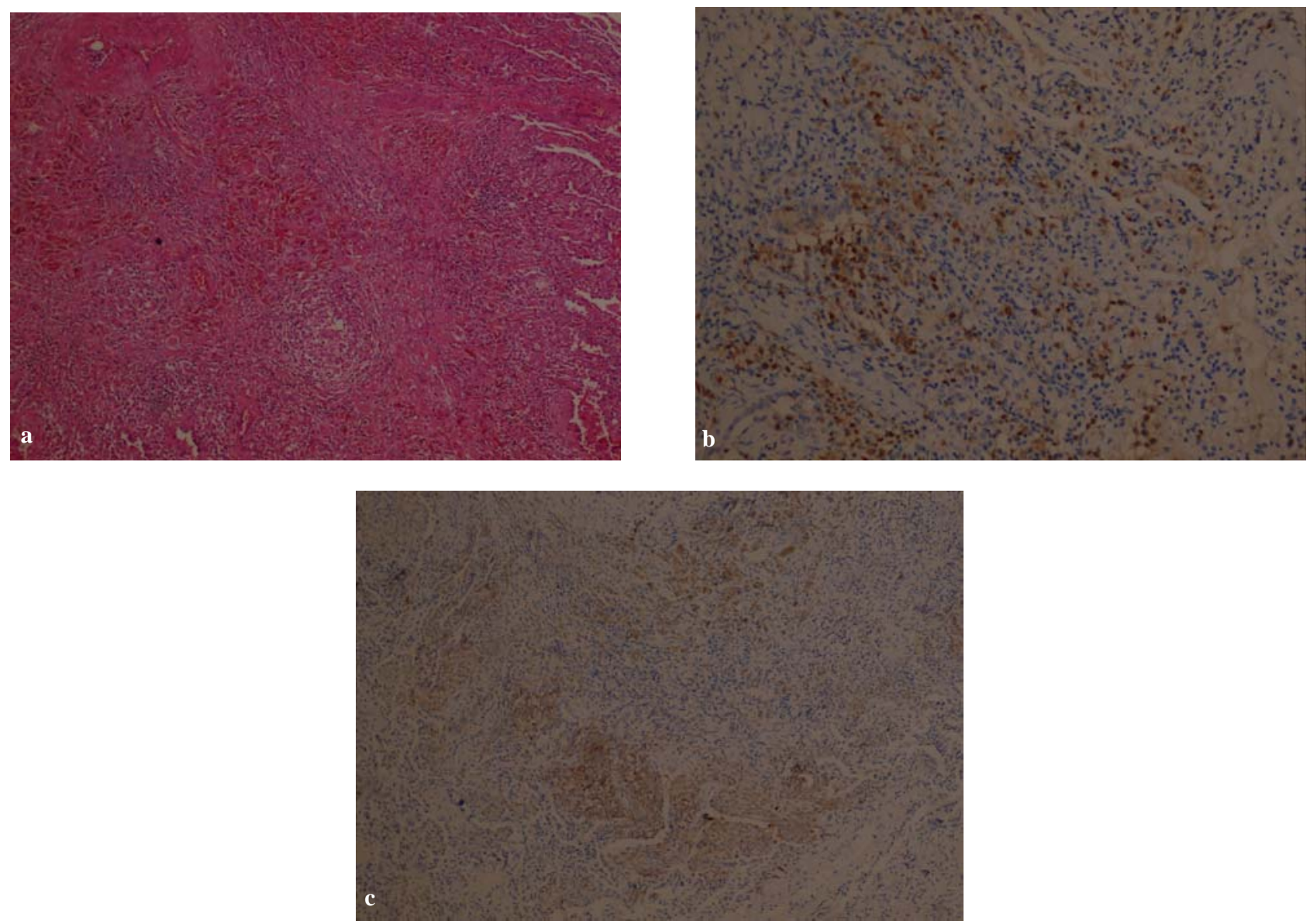

Fig 1a. large clusters of cells that are compatible with eosinophilic cytoplasm infiltrating Langerhans cells (H \& E x10). b) membranous staining of CD1a, Langerhans cells (immunohistochemical examination, x20). c) S100 proteins in the nuclear and cytoplasmic staining, Langerhans cells (immunohistochemical examination, x20). 
Case 2: A 34 years old man, who was an employee as a technician of an operating room, was referred with a two month history of cough and increased sensitivity to odors. Physical examination was normal. He had a 15 pack/year history of smoking. After non-specific antibiotherapy, HRCT was performed because of the progression in cough. Chest CT image revealed multiple parenchymal cystic nodular lesions ranging 5$20 \mathrm{~mm}$ in diameter, mostly with the wall-thickness of a few millimeters. Variable shapes with lobulated contours were detected as the result of the confluence of 2 or more lesions. Coronal reformat CT image demonstrated the mid and upper zone predilection (Image 2a,b). Blood gases and pulmonary function tests were normal. He was diagnosed as langerhans cell histiocytosis because of typically HRCT findings, smoking cessation was recommended, he left smoking and still in follow up as asymptomatic.

\section{Discussion}

The histiocytic disorders are rare conditions characterized by abnormal infiltration of specific organs by cells reproduced from monocyte/macrophage or dendritic cell origin. Langerhans cell histiocytosis $(\mathrm{LCH})$ is a specific type of histocytic syndromes which is characterized by infiltration of the tissues with Langerhans cells (10). LCH may affect an isolated organ or may act as a multisystemic disease (formerly termed as HandShuller-Christian or Letterer-Siwe disease) (11). In our cases, pulmonary involvement patterns were demonstrated solely. The signs and symptoms of PLCH are nonspecific and should prompt consideration of superimposed infection such as
Aspergillus or tumor $(12,13)$. Nonproductive cough, dyspnea and pleuritic chest pain are the most common symptoms $(1,5,14)$. Cough was the most frequent symptom in our cases.

The pulmonary involvement by the disease predominates in the mid to upper zones of the lung and spares the costophrenic angle which is in contrast with the typical lower zone involvement of idiopathic pulmonary fibrosis $(8,15)$. Lesions frequently extend widely into the parenchyma of the lung surrounding the bronchovascular structures, producing the socalled stellate lesions that are characteristic of this disorder. Interstitial fibrosis and small cyst formation occur with advancing disease; the mechanism for cyst formation is unknown (7).

Reticulonodular infiltrations are dominant findings in chest CT in early stage whereas cystic lesions and emphysema are more predominant in advanced stage. In the first case of our report; reticulonodular infiltrates were predominant, cavitated nodules located at the peribronchial and centrilobular region were determined.

These findings supported that the disease was at its' early stage. However; in the second case, findings including diffuse cyst formations located at the upper and middle zones of the pulmonary parenchyma indicated that the disease was on an advanced stage especially when compared with the first case.

The clinical signs and symptoms of PLCH are mostly may not be sufficient to distinguish itself from other non-specific pulmonary diseases. HRCT of the chest can provide an accurate final diagnosis if is demonstrating well-described CT findings of the issue, as particularly in the second case.
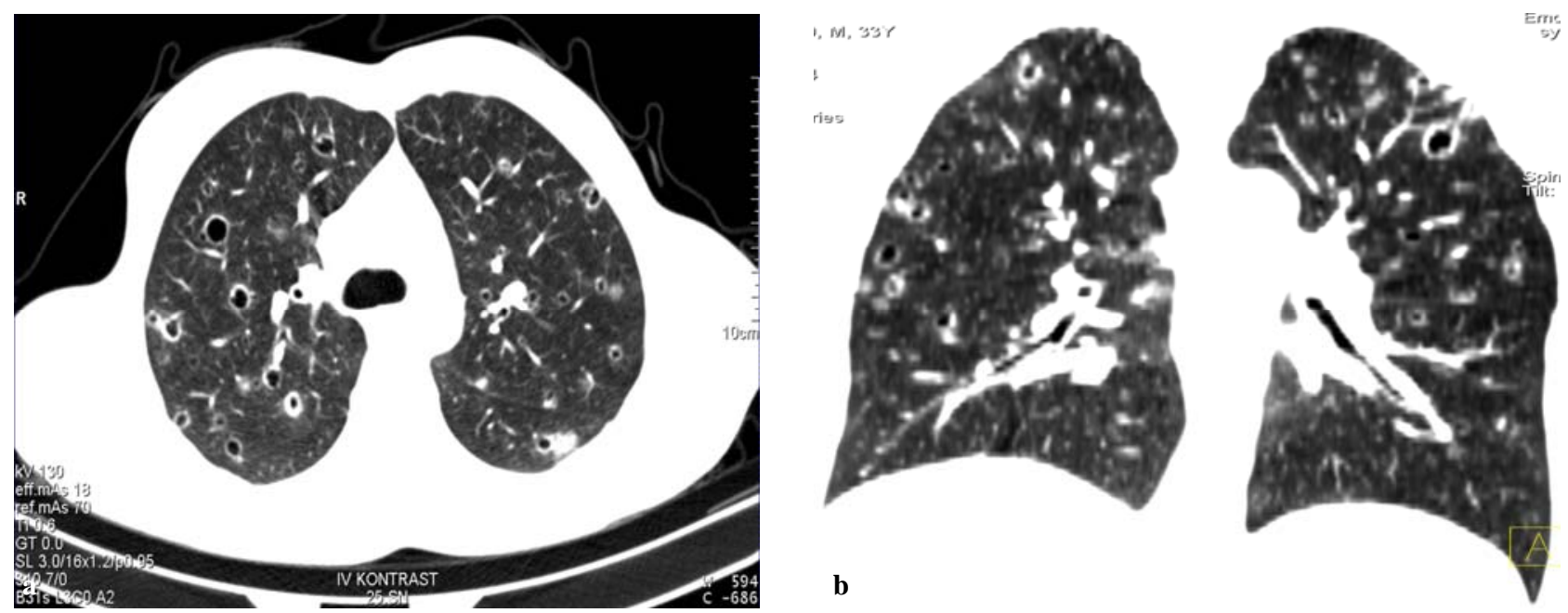

Image 2. Chest CT image from a 33-year-old male with biopsy-proven Pulmonary Langerhans cell histiocytosis. a) Cysts were $5-20 \mathrm{~mm}$ in diameter, mostly with the wall-thickness of a few millimetres. Variable shapes were seen as the result of the confluence of 2 or more cysts. b) Coronal reformat CT image demonstrated the mid and upper zone predilection. 
Pulmonary function tests are normal about $20 \%$ of patients. Restrictive pattern is commonly seen in earlier stages, while obstructive pattern becomes dominant in advanced stages (12,16). In our presentation, two cases had normal pulmonary function tests.

FDG-PET CT scans may show increased uptake in PLCH, especially at early stage in the course of disease. Krajicek et al. (17) evaluated a series of 11 patients with PLCH; five of the patients had abnormal FDG uptake in their lungs. The patients with FDG-PET positivity were more likely to have nodular pattern, suggesting earlier disease; those with negative FDG-PET scans were more likely to have a cystic pattern and less nodules, suggesting an advanced disease. In the first case of our report; FDG-PET was negative which could be explained by the existence of the small sized nodules in pulmonary parenchyma, because previous reports revealed that FDG activity in PET CT can be negative for the nodules with sizes less than $1 \mathrm{~cm}(18,19)$.

Surgical approaches including Video Assisted Thoracic Surgery or open lung biopsies may be involved to provide a definite diagnosis of $\mathrm{PLCH}$; thus, demonstration of the specific histopathological features can be obtained $(20,21)$. Langerhans cells also demonstrate positive immunohistochemical staining for S100 protein and have strong presence of CD1 antigen (CD1a) on the cell surface. In the first case open lung biopsy specimens showed CD1a, CD68, S100 detecting antigen-positive and langerhans cell histiocytosis diagnosed.

There is no widely accepted definite treatment guideline protocol for PLCH management in recent literature except a few recommendations that were reported regarding to treatment of adult patients with PLCH The most effective component of the PLCH treatment is indicated as smoking cessation. It was reported that the smoking cessation may solely prevent the progression of the disease so, it should be strongly encouraged $(14,21)$.

In conclusion, PLCH is an extremely rare benign disease. The patients could referred with different clinically and radiologically findings.

\section{References}

1. Tazi A, Soler P, Hance AJ. Adult pulmonary Langerhans' cell histiocytosis. Thorax 2000; 55: 405-416.

2. Vassallo R, Ryu JH, Colby TV, Hartman T, Limper AH. Pulmonary Langerhans'-cell histiocytosis. N Engl J Med 2000; 342: 19691978.
3. Vassallo R, Ryu JH. Pulmonary Langerhans' cell histiocytosis. Clin Chest Med 2004; 25: 561-571.

4. Sundar KM, Gosselin MV, Chung HL, Cahill BC. Pulmonary Langerhans cell histiocytosis: emerging concepts in pathobiology, radiology, and clinical evolution of disease. Chest 2003; 123: 1673-1683.

5. Tazi A. Adult pulmonary Langerhans' cell histiocytosis. Eur Respir J 2006; 27: 1272-1285.

6. Basset F, Corrin B, Spencer H, et al. Pulmonary histiocytosis X. Am Rev Respir Dis 1978; 118: 811-820.

7. Vassallo R, Limper AH. Pulmonary Langerhans cell histiocytosis. Interstitial Lung Disease, 4th ed, King TE Jr, Schwarz MI (Eds), B.C. Decker, Hamilton, ON, Canada 2003. p.838.

8. Kulwiec EL, Lynch DA, Aguayo SM, Schwarz MI, King TE Jr. Imaging of pulmonary histiocytosis X. Radiographics 1992; 12: 515-526.

9. Lacronique J, Roth C, Battesti JP, Basset F, Chretien J. Chest radiological features of pulmonary histiocytosis $\mathrm{X}$ : a report based on 50 adult cases. Thorax 1982; 37: 104-109.

10. Favara BE, Feller AC, Pauli M, et al. Contemporary classification of histiocytic disorders. The WHO Committee On Histiocytic/Reticulum Cell Proliferations. Reclassification Working Group of the Histiocyte Society. Med Pediatr Oncol 1997; 29: 157-166.

11. Komp DM. Historical perspectives of Langerhans cell histiocytosis. Hematol Oncol Clin North Am1987; 1: 9-21.

12. Crausman RS, Jennings CA, Tuder RM, et al. Pulmonary histiocytosis $\mathrm{X}$ : pulmonary function and exercise pathophysiology. Am J Respir Crit Care Med 1996; 153: 426-435.

13. Knight RK. Haemoptysis in eosinophilic granuloma. Br J Dis Chest 1979; 73: 181-186.

14. Caminati A, Harari S. Smoking-related interstitial pneumonias and pulmonary Langerhans cell histiocytosis. Proc Am Thorac Soc 2006; 3: 299306.

15. Kim HJ, Lee KS, Johkoh $\mathrm{T}$, et al. Pulmonary Langerhans cell histiocytosis in adults: highresolution CT-pathology comparisons and evolutional changes at CT. Eur Radiol 2011; 21: 1406-1415.

16. Vassallo R, Ryu JH, Schroeder DR, Decker PA, Limper AH. Clinical outcomes of pulmonary Langerhans'-cell histiocytosis in adults. $\mathrm{N}$ Engl J Med 2002; 346: 484-490.

17. Krajicek BJ, Ryu JH, Hartman TE, Lowe VJ, Vassallo R. Abnormal fluorodeoxyglucose PET in pulmonary Langerhans cell histiocytosis. Chest 2009; 135: 1542-1549.

18. Higashi K, Ueda Y, Seki H, et al. Fluorine-18-FDG PET imaging is negative in bronchioloalveolar lung carcinoma. J Nucl Med 1998;39: 1016-1020. 
19. Erasmus JJ, McAdams HP, Patz EF, et al. Evaluation of primary pulmonary carcinoid tumors using FDG-PET AJR 1998; 170: 1369-1373.

20. Suri HS, Yi ES, Nowakowski GS, Vassallo R. Pulmonary lan-gerhans cell histiocytosis. Orphanet J Rare Dis 2012; 7: 16.
21. Juvet SC, Hwang D, Downey GP. Rare lung diseases III: pul-monary Langerhans' cell histiocytosis. Can Respir J 2010; 17: 55-62.

East J Med Volume:21, Number:1, January-March/2016 